\title{
As práticas de desinvestimento pedagógico na Educação Física escolar
}

\author{
Thiago da Silva Machado* \\ Valter Bracht** \\ Bruno de Almeida Faria ${ }^{* * *}$ \\ Claudia Moraes ${ }^{* * * *}$ \\ Ueberson Almeida ${ }^{* * * * *}$ \\ Felipe Quintão Almeida ${ }^{* * * * * *}$
}

\begin{abstract}
Resumo: Investiga o desinvestimento do professor de Educação Física (EF) em relação á sua função pedagógica, utilizando a metodologia da história de vida e o estudo de caso etnográfico. Estuda também elementos envolvidos na produção de uma cultura escolar. Os dados produzidos são analisados a partir de três categorias: a) a EF como componente curricular: a escola também desinveste? b) a dificuldade de operar a mediação entre a teoria e a prática; c) o esporte como conteúdo das aulas de Educação Física.

Palavras-chave: Docentes. Conflito. Papel profissional. Esportes
\end{abstract}

Licenciado em Educação Física pela Universidade Federal do Espírito Santo (UFES). Membro do Laboratório de Estudos em Educação Física (Lesef/CEFD/Ufes). Vitória, ES, Brasil. E-mail: thiago.m_ef@hotmail.com

"* Professor de Educação Física. Professor titular do Centro de Educação Física e Desportos (CEFD) da Universidade Federal do Espírito Santo (Ufes). Doutor pela Universidade de Oldenburg (Alemanha). Membro do Laboratório de Estudos em Educação Física (Lesef/CEFD/Ufes). Vitória, ES, Brasil. E-mail: valter.bracht@pq.cnpq.br

"*t* Licenciado em Educação Física pela Universidade Federal do Espírito Santo (UFES). Membro do Laboratório de Estudos em Educação Física (Lesef/CEFD/Ufes). Vitória, ES, Brasil. E-mail: brunimfaria@hotmail.com

*t*t Licenciada em Educação Física pela Universidade Federal do Espírito Santo (UFES). Mestre em Educação pela Universidade Federal de Santa Catarina (CED/UFSC). Membro do Laboratório de Estudos em Educação Física (Lesef/CEFD/Ufes). Vitória, ES, Brasil . E-mail: cea_moraes@hotmail.com

*tut* Licenciado em Educação Física pela Universidade Federal do Espírito Santo (UFES). Mestre em Educação Física pela Universidade Federal do Espírito Santo (Ufes). Membro do Laboratório de Estudos em Educação Física (Lesef/CEFD/Ufes). Vitória, ES, Brasil. Email:uebersonribeiro@terra.com.br

Licenciado em Educação Física pela Universidade Federal do Espírito Santo (UFES). Doutor em Educação pela Universidade Federal de Santa Catarina (CED-UFSC). Membro do Laboratório de Estudos em Educação Física (Lesef/CEFD/Ufes) e do Núcleo de Estudos e Pesquisas Educação e Sociedade Contemporânea (CED/UFSC). Vitória, ES, Brasil. E-mail: fqalmeida@hotmail.com 


\section{INTRODUÇÃO}

Um dos fenômenos que mais chama a atenção no panorama atual da prática pedagógica em Educação Física (EF) nas nossas escolas é que muitos professores resumem sua ação a observar os seus alunos na quadra enquanto eles realizam atividades que eles mesmos escolheram ou, então, aquelas que são possíveis em função do tipo de equipamento e material existente (quase sempre futebol ou futsal, queimada ou mesmo voleibol). Em alguns contextos, esses professores são conhecidos como professores bola e, em outros, como professores rola-bola. São expressões pejorativas utilizadas para caracterizar (e caricaturizar) a prática de professores de EF que, por conta de uma série de fatores, muitas vezes, fica reduzida ao ato de distribuir os materiais didáticos aos alunos e sentar-se à sombra para, por exemplo, ler o jornal. Embora essa figura seja muito presente (talvez de forma crescente), esse fenômeno permanece pouquíssimo estudado, atribuindo-se $a$ culpa, de forma simplista, aos próprios professores (falta de compromisso; vagabundo/preguiçoso; não tem vergonha etc.).

Na tentativa de melhor compreender esse acontecimento, realizamos um trabalho de campo (estudo de caso etnográfico) visando a identificar/analisar possíveis fatores implicados nessa postura assumida por parte dos docentes em relação às suas práticas pedagógicas. Na perspectiva de valorizar as chamadas microestruturas e ouvir o que os agentes escolares têm a dizer, elegemos, como princípio norteador, a investigação de caráter qualitativo. Ainda do ponto de vista metodológico, a história de vida, dentro de sua perspectiva sociológica (BOGDAN; BIKLEN, 1994), foi utilizada com o intuito de reconstituir a carreira profissional dos sujeitos, procurando enfatizar o papel das organizações, dos acontecimentos marcantes e a presença de outras pessoas que possam ter exercido influências significativas na moldagem das definições de si e das suas perspectivas sobre a vida e sobre o trabalho, compondo, por assim dizer, as diversas posições, os estágios e as formas de pensar dos indivíduos ao longo de suas vidas profissionais. Cabe destacar que empregamos o termo carreir, objetivando designar as diversas posições, os estágios e as formas de pensar dos indivíduos ao longo de suas vidas (HUGHES, apud BOGDAN; BIKLEN, 1994).

Movimento, Porto Alegre, v. 16, n. 02, p. 129-147, abril/junho de 2010. 
Procuramos, também, cruzar essas informações com os demais elementos envolvidos na produção da cultura escolar (FORQUIN, 1993) em que os docentes investigados estavam inseridos. Essa estratégia mostrou-se muito profícua, pois a reflexão sobre a cultura escolar consiste na compreensão de que os sujeitos escolares " [...] carregam para o tempo-espaço concreto da escola a sua história de vida, as marcas de sua cultura originária, seus interesses, seus sonhos, suas paixões, suas carências [...]" (VAGO, 2003, p. 213).

As visitas às escolas aconteceram duas vezes por semana e o trabalho teve duração de oito meses. ${ }^{1}$ Empregamos o diário de campo, a observação participante e as entrevistas aprofundadas como técnicas principais da produção dos dados. Após cada visita, as observações foram registradas no diário de campo e as entrevistas (gravadas em áudio) foram transcritas posteriormente. Neste texto, trazemos alguns elementos conceituais e perspectivas de análise produzidas a partir da discussão de um dos casos que estudamos: o do professor José. ${ }^{2}$

\section{0 desinVESTIMENTO PEDAGógICO: ENTRE A AULA E O NÃO AULA}

Estabelecer uma definição acerca do termo desinvestimento pedagógico, a partir dos elementos determinantes desse processo, é tarefa díficil e exige cuidado. Durante os estudos de revisão de literatura, deparamo-nos com uma série de conceitos que apontam para o fenômeno. Tais definições o apresentam sempre como um produto resultante de um emaranhado de fatores relacionados entre si, o que nos permite classificá-lo como um fenômeno de carater multifatorial.

A inspiração para o emprego do termo desinvestimento advém da taxionomia elaborada por Huberman (1995). De acordo com o modelo adotado por esse autor, o professor atravessa uma fase de

\footnotetext{
${ }^{1}$ Chegamos aos professores estudados graças à indicação de um funcionário da Secretaria Municipal de Educação da Serra/ES (também professor de Educação Física), que nos sugeriu as escolas em que poderíamos encontrar professores com as características do que estamos chamando de estado de desinvestimento. Os professores, após conhecimento do projeto de pesquisa, consentiram em colaborar conosco na investigação.

${ }^{2} \mathrm{O}$ nome é fictício. Cabe ressaltar que o caso que apresentamos compõe, juntamente com outros estudos de caso, uma pesquisa mais ampla, iniciada no ano de 2007, ainda em andamento. Participam dessa investigação cinco grupos de pesquisa em EF pertencentes a diferentes instituições, três do Brasil e duas da Argentina.
} 
desinvestimento, presente nos períodos finais da carreira docente, na qual o trabalho perde centralidade em sua vida. Assumimos esse modelo como uma ferramenta que nos ajuda a pensar (um tipo ideal), sem permitir que ele engesse a própria história de vida profissional e pessoal de cada professor em categorias estanques e regulares. Expressão disso é o fato de encararmos, ao contrário de Huberman (1995), o desinvestimento não como uma fase, mas sim como um estado, o que nos distancia de uma compreensão do fenômeno como algo dotado de certa cronologia ou linearidade. No caso específico da EF, o desinvestimento, por nós adjetivado de pedagógico, corresponderia àqueles casos em que os professores de EF escolar permanecem em seus postos de trabalho mas abandonam o compromisso com a qualidade do trabalho docente.

Assim, as perguntas que nos colocamos apontam para a direção de saber em que medida é possível conceituar o estado de desinvestimento. Tal questão ganha pertinência, principalmente, ao pensarmos que o estabelecimento de um conceito, com contornos rígidos, poderia nos levar a incorrer em equívocos metodológicos, particularmente no tocante ao trabalho de campo. A ideia assumida, então, foi a do estabelecimento de um diálogo com o mundo empírico a partir de uma ampla caracterização do desinvestimento pedagógico, a ser usada com flexibilidade, rigorosidade e confrontada com a realidade. Evitaríamos, desse modo, qualquer limitação terminológica causada pela seletividade oriunda de um pré-conceito teórico. Dessa forma, embasados por nossos estudos e pela relação com o campo de pesquisa, foi possível estabelecer as primeiras considerações sobre esse fenômeno.

$\mathrm{O}$ professor que temos denominado em estado de desinvestimento pedagógico é aquele cuja prática recebe denominações como rola bola e/ou como pedagogia da sombra. Geralmente, ele se encontra em estados nos quais não apresenta grandes pretensões com suas práticas; talvez a pretensão maior seja a de ocupar seus alunos com alguma atividade. Com frequência, converte-se em simples administrador de material didático, atividade que não exigiria, em princípio, formação superior. Outras vezes, assume uma postura de compensador do tédio dos alunos produzido nas ou- 
tras disciplinas (como Matemática, Português etc.). Outra característica marcante com a qual temos nos deparado durante as observações é que, como consequência desse não se empenhar ou dessa ausência de pretensão com a prática pedagógica, o que se nota é a configuração de um fenômeno que podemos denominar de não aula. De forma incipiente, pode-se caracterizar esta não aula quando: no tempo-espaço designado/reservado para que a prática pedagógica do professor ocorra, este não intervém de forma objetiva-intencional, privando os alunos da possibilidade de acesso à aprendizagem de um conteúdo específico e/ou do desenvolvimento de uma determinada habilidade. Geralmente este espaço pode confundir-se, ainda, com outros momentos nos quais os alunos simplesmente se divertem (recreio ou aula vaga), sem que haja qualquer diretividade do professor com intenções pedagógicas de aprendizagem.

Em estudo correlato ao nosso, González e Fensterseifer (2006, p. 739-740) buscaram estabelecer critérios que permitissem a identificação/caracterização do conceito de aula, o que nos auxilia na definiç̧ão do processo inverso (a não aula). Assim, os autores definem a aula como: a) um fenômeno vivo; b) dotada de intencionalidade; c) as aprendizagens e/ou desenvolvimentos procurados são fundamentais para todos os alunos da turma; d) uma aula acontece quando desempenha seu papel no projeto que articula o trabalho no médio e longo prazo; e) uma aula supõe, por parte do professor, um projeto de mediação daquele saber que se pretende que seus alunos construam e/ou da capacidade que pretende que os alunos desenvolvam.

Ainda segundo os autores supracitados, a aula, como um fenômeno vivo, pressupõe que esse momento se configure como repleto de situações inesperadas, capazes de surpreender o professor. Mas isso não exime o professor de um planejamento prévio. No que diz respeito à intencionalidade, a ação docente deve estar pautada em uma reflexão acerca do que vai ser proposto, bem como na busca de seus porquês. Já as aprendizagens e/ou os desenvolvimentos procurados são fundamentais para todos os alunos da turma. Desta forma, a participação ou não na aula não deve ser simplesmente uma escolha do aluno, o que não significa ignorar o interesse dos estudantes como fator importante para potencializar sua participação. 
Uma aula acontece quando desempenha seu papel no projeto que articula o trabalho em médio e em longo prazo, ou seja, a aula não pode ser entendida como um fenômeno isolado, que não demande continuidade, visando a uma aprendizagem efetiva. Uma aula supõe, por parte do professor, um projeto de mediação daquele saber que pretende que seus alunos construam e/ou da capacidade que espera que seus alunos desenvolvam. Isso evidencia-se na forma como o professor propicia que os alunos se envolvam com o "objeto" de trabalho, com vistas a potencializar a aprendizagem.

Por fim, destacamos que nossa compreensão do estado de desinvestimento pedagógico está orientada pelo pressuposto de que a prática pedagógica deve ser entendida como uma construção que envolve, entre outras coisas, as crenças, as motivações, as tensões e as conquistas próprias da formação humana desses professores. Nesse sentido, compreender o fenômeno implica, também, avaliar como se articulam os projetos de vida pessoal e profissional desses professores e o próprio ambiente de trabalho.

\section{CASO DO PROEFESSOR JOSÉ: ASPECTOS MARCANTES DE SUA PRÁTICA PEDAGÓGICA EM UMA CULTURA ESCOLAR ESPECÍFICA}

O professor José nasceu no interior de Minas Gerais, onde viveu até completar 15 anos de idade. Sempre estudou em escolas da rede pública de ensino, tendo se formado em Educação Física pela Universidade Federal do Espírito Santo, no ano de 1987, em um currículo conhecido, atualmente, como tradicional-esportivo (BETTI; BETTI, 1996). Desde que se formou, atua como professor de EF escolar, o que, em seu entendimento, é bastante desgastante. Atualmente, divide-se entre o trabalho na escola (para ser mais exato, José trabalha em duas escolas: a primeira refere-se à instituição na qual desenvolvemos este estudo; a segunda diz respeito à escola em que faz complementação de carga horária), no município de Serra/ ES, e o de instrutor no Programa Municipal de Serviço de Orientação ao Exercício (SOE), na cidade vizinha (Vitória/ES).

A escola na qual a pesquisa foi desenvolvida situa-se no município de Serra/ES. Trata-se de uma antiga escola estadual que passou 
pelo processo de municipalização e que, como afirmam alguns funcionários, ainda hoje sofre algumas adaptações e problemas decorrentes desse processo. Atualmente, atende a 242 alunos e conta com 17 professores e 21 funcionários. Com relação à estrutura, pode ser caracterizada como uma escola de pequeno porte: contém um pequeno número de salas de aula, não tem quadra poliesportiva (existe na escola um pátio que foi adaptado para se tornar quadra de futsal), a biblioteca encontra-se em um espaço improvisado (o que, em certa medida, dificulta o trabalho com o acervo) e a sala de informática ainda não foi instalada, devido à ausência de um espaço adequado. Em contrapartida, há uma área arborizada que oferece diversas possibilidades de trabalho. É nesse espaço que, comumente, observa-se, afixada entre duas árvores, a rede de voleibol nas aulas de EF.

Segundo a diretora da escola, o problema da violência atinge o bairro e, consequentemente, a instituição. Durante algumas visitas, pudemos observar isso de forma clara, principalmente quando alguns rapazes jovens pulavam o muro da escola e resistiam aos pedidos de que se retirassem. Algo que também afeta aquela escola é a existência de muitas casas de prostituição no bairro.

De maneira geral, podemos dizer também que, durante o estudo, não nos foi perceptível a existência de conflitos relacionais de alargada amplitude entre a equipe pedagógica e os professores da escola ou mesmo entre os próprios docentes, a ponto de causar um clima desfavorável para o trabalho. Isso não implica, necessariamente, que haja grande afinidade entre eles ou, ainda, que estejam satisfeitos com o trabalho que os colegas vêm realizando. Afinal, há, por parte da escola, um descontentamento com o trabalho do professor José.

Ao tomar conhecimento do projeto de pesquisa, ela se mostrou muito interessada pelo estudo e disse que seria ótimo se eu escolhesse sua escola, pois o professor não dá aula (DIRETORA da escola-diário de campo).

O professor José já anda meio que em final de carreira, mas é uma pessoa ótima. Só que já está meio cansado, mas você não tem que tomar suas aulas como exemplo, para quem está começando como você, não (COORDENADORA da escola - diário de campo). 
Você está fazendo estágio aqui? (Respondi-lhe que não, falei que se tratava de uma pesquisa. Ela emendou): Ah, sim. Por que fazer estágio com este professor aí não dá. Ele não está com nada (SECRETÁRIA da escola - diário de campo).

Percebemos, ainda, que há grande dificuldade na implementação de um trabalho coletivo na escola:

Olha, é algo que a gente vem tentando implantar, mas é difícil. Sabemos que é importante, mas, de certa forma, está muito enraizada uma cultura de professores que querem trabalhar de forma mais individual. De $1^{\mathrm{a}}$ a $4^{\mathrm{a}}$ séries até dá pra fazer algo, sempre há reuniões, mas de $5^{\mathrm{a}}$ a $8^{\mathrm{a}}$ séries é mais difícil. Mas tem, por exemplo, a reunião de planejamento no início do ano onde a gente senta para estar falando para os professores sobre o que se pretende para aquele ano, para estar passando como funciona a escola para os novatos (DIRETORA da escola - entrevista).

Com relação à EF, o mergulho no cotidiano escolar deixou claro o descrédito da disciplina em relação às demais. Isso porque, apesar das constantes reclamações por parte dos membros da escola sobre a forma como o professor José conduz suas aulas, nota-se que a cobrança não é tão enfática. E mais, a escola almeja uma mudança por parte do professor, mas não tem clareza sobre qual é a função pedagógica desse componente curricular. A própria pedagoga afirma que não tem acompanhado a disciplina "de perto", apesar de ter recebido do professor seu plano de curso:

Bom... eu tenho que ver as aulas do José, eu tenho que conversar com ele de novo. Eu tenho conversado menos com ele. Inclusive, a coordenadora tem conversado com ele mais do que eu. Mas eu vou conversar mais com ele sobre isso, porque eu estou meio por fora. Eu sei o que ele passou pra mim aqui no projeto, mas, sinceramente, eu não estou muito por dentro. Sabe, você veio me perguntar isso agora e eu fiquei assim... não sei! Eu preciso, realmente, está revendo isso daí (PEDAGOGA da escola entrevista). 
Algo que agrava a situação é o fato de o professor de EF trabalhar em três lugares diferentes (duas escolas e um módulo de orientação ao exercício), dificultando, dessa forma, seu envolvimento no planejamento semanal, nas reuniões coletivas, na elaboração do Projeto Político Pedagógico e nas demais atividades que acontecem na escola. A impressão que se tem é de que, para a escola, basta ao professor de EF a assiduidade e a pontualidade, além do cumprimento de atividades burocráticas, por exemplo, o preenchimento das pautas de chamada. O próprio professor José destaca isso:

A cobrança da direção é natural. É mais aquelas coisas pontuais: assiduidade, frequência e você estar à frente dos alunos para não permitir que aconteça nada de surpreendente. O que é mais exigido é assiduidade mesmo, comparecer no ambiente de trabalho, que é obrigatório, lógico. Enfim, o resto é resto (PROFESSOR JOSÉ - entrevista).

Observando a sua prática docente atual, podemos afirmar que as aulas de EF de José, na instituição investigada, pouco diferem das atividades livres realizadas pelos alunos nos espaços de recreio ou das aulas vagas. A principal diferença encontra-se no fato de não estarem disponíveis aos alunos materiais que, na maioria das vezes, só podem ser acessados para as aulas de EF. A dinâmica de aula é sempre a mesma: os alunos saem das salas e estão livres para realizar a atividade que lhes convier. Muitos escolhem, inclusive, não participar de atividade alguma, passando a aula toda conversando com outros colegas ou realizando tarefas de outras disciplinas. Essa situação torna complexa, também, a tarefa de constatar se existe algum tipo de planejamento, já que, em momento algum, observa-se a proposição ou a realização de uma atividade que envolva todo o coletivo de alunos. O que se nota, portanto, é que, no momento da aula, o professor José comporta-se apenas como um administrador do material didático. Para ele, a função da EF é "[...] possibilitar que os alunos tenham contato com o desporto, já que, muitas vezes, eles não têm essa oportunidade em outros espaços" (PROFESSOR JOSÉ - entrevista). Afirma, ainda, que a EF pode proporcionar um conhecimento além de um saber-fazer corporal, mas que não trabalha nessa perspectiva. 
Por fim, destacamos, como característica de seu trabalho, a inexistência de uma avaliação coerente, pois o professor não acompanha todos os alunos durante as aulas (já que eles se encontram dispersos pela escola), além de não realizar nenhum registro dos alunos faltosos. Conforme nossa descrição do diário de campo,

De repente, o professor de EF sai da sala dos professores e vai até uma aluna da $8^{\circ}$ série para pedir-lhe ajuda em relação ao preenchimento de sua pauta. A questão era saber quais alunos, entre aqueles que tinham o nome na lista de chamada, ainda frequentavam a escola. Em seguida, ele se dirige a mim para dizer que iria até a sala da $6^{\circ}$ série fazer o mesmo.

\section{COMPREENDENDO O DESINVESTIMENTO PEDAGÓGICO}

A partir do material empírico confrontado com a literatura, fizemos a opção aqui por colaborar com a compreensão do fenômeno do desinvestimento pedagógico de professores de Educação Física com a construção de três grandes categorias. O esforço que segue é uma primeira aproximação, dada a complexidade do fenômeno em estudo.

\subsection{A EF COMO COMPONENTE CURRICULAR: A ESCOLA TAMBÉM INVESTE?}

A EF é, de acordo com a Lei de Diretrizes e Bases da Educação Nacional (LDBEN), ou seja, Lei n ${ }^{\circ}$ 9.394, de 20 de dezembro de 1996, modificada pela Lei $\mathrm{n}^{\mathrm{o}} 10.328$, de dezembro de 2001, componente curricular obrigatório. Apesar da legalidade, vigente há mais de uma década, cabe perguntar se os professores de EF escolar, bem como os demais agentes escolares, têm clareza da especificidade pedagógica de tal componente. O que nossa pesquisa tem evidenciado?

Pudemos observar, durante nossos trabalhos de campo, que a escola e o próprio professor têm um entendimento de EF muito diferenciado daquilo que a produção acadêmica na área vem construindo. Permanece um enorme fosso entre os recentes avanços teóricos da $\mathrm{EF}$ como área de conhecimento e a intervenção pedagógica no âmbito escolar (CAPARROZ; BRACHT, 2007). Como já evidenciamos, a 
prática com características de desinvestimento pedagógico é objeto de diversas reclamações por parte de membros da equipe pedagógica da escola. O problema, contudo, reside no fato de que, em momento algum, essa cobrança esteve voltada para a função pedagógica que a disciplina (como um componente curricular com conteúdo/saber a ser ensinado) deveria cumprir. No máximo, o que se ouvia, por parte da equipe pedagógica, eram frases do tipo: “A EF está na escola para somar, para auxiliar no trabalho da escola, seja na questão da disciplina, do comportamento" (diário de campo). Ou seja, notamos que a escola possui uma visão acerca da função pedagógica da EF muito distante da perspectiva que a entende como um componente curricular com um saber a ser transmitido/tematizado e que se configura naquilo que se tem denominado de cultura corporal de movimento.

Nesse sentido, talvez seja possível pensarmos que existe, por parte da escola, dificuldade em perceber que outro tipo de contribuição pedagógica a EF pode oferecer. Poderíamos, ainda, propor uma indagação inversa: no caso da existência dessa percepção, até que ponto o saber específico da disciplina é valorizado pela escola?

Queremos, assim, chamar a atenção para o fato de que a escola, em algumas oportunidades, ao não conferir à EF o estatuto de disciplina escolar mediadora de um conhecimento/saber, pode dificultar, em razão desse não reconhecimento, a produção de práticas pedagógicas de qualidade. É com base no que vimos descrevendo que entendemos ser pertinente a seguinte reflexão: é comum ouvir que esse ou aquele professor de EF apresenta uma prática com características de desinvestimento pedagógico (recebem a denominação de rola-bola), mas qual é a participação da escola (de uma cultura escolar específica) nesse processo? Não estariam as culturas escolares esvaziando de sentido essa prática pedagógica e, com isso, favorecendo o desinvestimento pedagógico? Quais posturas, atitudes e saberes a escola exige do professor de EF? O que a escola busca garantir que os alunos aprendam nas aulas de EF? Ou, simplesmente, podemos interpelar: a escola também desinveste? 


\subsection{A DIFICULDADE DE OPERAR A MEDIAÇÃO ENTRE A TEORIA E A PRÁTICA}

Durante os trabalhos de observação, uma questão muito presente dizia respeito à relação estabelecida pelo professor participante da pesquisa com a produção acadêmica no campo. A sensação que tínhamos era de que esse professor tinha certa dificuldade e, às vezes, repulsa em lidar com os conhecimentos ditos teóricos (presentes na literatura mais recente) construídos na área. As entrevistas e os diálogos estabelecidos, durante o período do trabalho de campo, demonstraram que a reação esboçada por esse docente pode encontrar sua origem, entre outras coisas, no tipo de formação inicial pela qual passou. O professor em questão obteve sua licenciatura no ano de 1987, cuja formação pode ser assim caracterizada:

O currículo tradicional-esportivo enfatiza as chamadas disciplinas 'práticas' (especialmente esportivas). O conceito de prática está baseado na execução e demonstração, por parte do graduando, de habilidades técnicas e capacidades físicas (um exemplo são as provas 'práticas', onde o aluno deve obter um desempenho físico-técnico mínimo). Há separação entre teoria e prática. Teoria é o conteúdo apresentado na sala de aula (qualquer que seja ele), prática é a atividade na piscina, quadra, pista, etc. (BETTI; BETTI, 1996, p. 10. grifo do autor).

Podemos notar uma dificuldade do professor em conceber a relação teoria e prática de forma diferente daquela vivenciada em seu curso de formação inicial em EF. Parece haver, principalmente, uma grande dificuldade em promover, na intervenção, uma mediação entre esses aspectos (teóricos e práticos). Para José, há o entendimento de que, no momento em que está na quadra com seus alunos, mobiliza prioritariamente os conhecimentos adquiridos por meio das disciplinas práticas com as quais tivera contato em sua formação inicial, bem como aqueles saberes acumulados ao longo de sua carreira. Quanto às disciplinas de caráter pedagógico cursadas na formação inicial, José lhes atribui caráter secundário. De acordo com ele, o ensino dessas disciplinas era superficial, pois não havia aulas práticas, o que dificultava o aprendizado. 
De certa forma, a dicotomia entre teoria e prática alimentada pelo professor colaborador do trabalho e a dificuldade em perceber contribuições dos diferentes saberes a sua prática ajudam a compreender a sua aversão aos conhecimentos teóricos produzidos no campo nos últimos anos. Expressão disso é o fato de o professor José e a própria escola terem dificuldade de expressar com clareza qual a função do componente curricular EF. Parece haver a compreensão (da escola e do professor) de que a teoria, na Educação Física, corresponde àqueles momentos de ensino das regras em sala de aula, utilizando quadro de giz ou recursos similares, reduzindo o saber conceitual da EF a esses aspectos:

[...] a EF está na escola para somar, para auxiliar no trabalho da escola, seja na questão da disciplina, do comportamento. E não é só ficar brincando, tem que ter teoria também. Ensinar sobre as regras, eu me lembro que, quando eu fiz EF, eu tinha a parte de teoria também (DIRETORA da escola - entrevista).

Eu, particularmente, não sou muito favorável, não sou muito teórico não. Gosto mais é do fazer mesmo [...]. Eu acho que é um desperdício. $O$ aluno já é muito teorizado, já. Já vive muito num confinamento. Vive na educação bancária o tempo todo, e a gente ainda vai gastar tempo precioso pra ficar enchendo saco dos outros com teoria, com falação (PROFESSOR JOSÉ - entrevista).

Entendemos que a falta de compreensão acerca da especificidade do componente curricular EF, somada à dificuldade de operar a mediação entre teoria e prática, refletem diretamente na forma como o professor orienta sua prática pedagógica. Pensando especificamente a questão do desinvestimento pedagógico, poderíamos avaliar também em que medida tais dificuldades não provocam no professor um sentimento de impotência ou mesmo de descrença no que diz respeito às possibilidades abertas (de maneira contextualizada) pelas teorias/abordagens pedagógicas.

Diante da dificuldade em compreender aquilo que vem sendo proposto pelo Movimento Renovador para o ensino da EF, o professor José fecha-se a qualquer tipo de diálogo ou aprendizagem (por exem- 
plo, nos encontros de formação continuada) no que tange à questão. Notamos, portanto, a criação de uma espécie de resistência por esse professor, um movimento de autodefesa. Cabe também a hipótese de que esse professor realiza uma leitura enviesada de alguns aspectos contidos nas propostas pedagógicas que tratam do assunto. Esse é o caso, por exemplo, do esporte, prática que, a seu ver, justifica a presença da EF na escola. O docente, ao não desenvolver suas aulas ensinando as técnicas/destrezas esportivas, prática que se disseminou nas décadas de 70 e 80 do século passado, acaba por deixar as aulas totalmente soltas, abandonando, inclusive, o trabalho na perspectiva tradicional de ensino.

\title{
4.3 O ESPORTE COMO CONTEÚDO NAS AULAS DE EDUCAÇÃO FÍSICA
}

O professor José atribui ao esporte um caráter de autossuficiência muito grande, a ponto de argumentar que a prática esportiva é a dimensão da cultura que justifica a EF na escola. Afinal, muitos professores de EF são tidos como bons, pela escola, quando conseguem vencer campeonatos. Isso pareceu-nos claro tanto nas entrevistas como nos diálogos e também nas observações durante o período da pesquisa. Percebemos, ainda, que o professor José trata ambos (EF e esporte) como se fossem equivalentes, ou seja, não promove uma distinção entre esporte e EF.

\begin{abstract}
Olha bem, eu acho que a EF está na escola pra quebrar o gelo mesmo, pra não deixar que a escola seja uma coisa, um lugar morto. [...] aqui fora, nas aulas de EF, o aluno tem prazer em estar participando da atividade esportiva, por isso ela (a EF) se justifica por si só (PROFESSOR JOSÉ - entrevista).
\end{abstract}

De fato, o esporte apresenta-se, na atualidade, como um fenômeno de grande expressividade, dotado de legitimidade social em todas as sociedades. Entretanto, em meio a essa explosão esportiva, "[...] levantam-se algumas vozes, principalmente no meio acadêmico, que expressam dúvidas quanto aos valores humanos e sociais deste fenômeno" (BRACHT, 2005, p. 10). Especificamente no campo da $\mathrm{EF}$, não é de hoje que existem questionamentos acerca da pertinência desse esporte normatizado para as aulas de EF escolar, bem como a 
proposição de um esporte $d a$ escola em detrimento de um esporte na escola (CAPARRÓZ, 1997; VAGO, 1996). Entendemos que uma EF calcada no esporte (ou em qualquer outro elemento da cultura corporal de movimento), sem que este seja tratado pedagogicamente, permanece carente de justificação dentro do ambiente escolar. Não se trata, pois, de negar o esporte como elemento de ensino da EF ou ser contrário ao seu ensino na escola, mas de apontar a necessidade de que este receba um trato pedagógico. Tornar o esporte objeto de intervenção pedagógica intencional permite que seu ensino ultrapasse o desenvolvimento de situações nas quais os alunos apenas vivenciam esse elemento da cultura corporal, com vistas a possibilitar, também, uma compreensão crítica de tudo aquilo que é por ele abarcado, assim como dos demais elementos que envolvem o momento aula. Nesse sentido, a didática nas aulas de EF

\begin{abstract}
[...] não pode se contentar em fomentar uma forma econômica, técnica e racional de aprendizagem, até para não cair no constante risco da 'cegueira de um saber modesto'. Um pensamento didático deveria, muito antes, ser orientado para a questão de como as relações com o mundo dos objetos podem ser intensificadas e como, a partir disso, podem surgir questões mais interessantes para as práticas de movimentos (MARAUN, 2006, p. 200).
\end{abstract}

No caso do docente investigado, existe também dificuldade e/ ou certa resistência em relação a um trato pedagógico do conteúdo esporte. Entendemos que isso, entre outros fatores, pode ser decorrente de aspectos tais como os que discutimos nos tópicos anteriores. Pensamos, ainda, ser possível atrelar essa resistência à relação estabelecida pelo professor José com uma determinada cultura esportiva, ou seja, ao conjunto de disposições relativas ao fenômeno esportivo incorporadas pelo professor José ao longo de sua trajetória de vida, seja por meio da vivência dessa prática corporal, seja por outros meios (mídia etc.). De acordo com seus relatos, a partir de sua adolescência, sempre se viu envolvido com o esporte, na escola e fora dela, por meio da participação em competições esportivas na região em que residia. Segundo ele, apesar de não ter seguido a carreira de atleta, o esporte sempre foi uma de suas grandes paixões, sendo 
determinante, inclusive, em sua escolha pelo curso de EF.

Para Vieira (2007) e Figueiredo (2004), não é de se estranhar que as experiências ao longo da vida sejam determinantes na escolha de uma carreira; disso não se excluem as experiências esportivas, como acontece, em muitos casos, com os professores de EF. O problema, segundo as autoras, é quando essas experiências/práticas anteriores determinam uma identidade profissional a ponto de colocar em xeque a própria formação acadêmica na área. Mesmo tendo passado por um curso de formação, os professores reproduzem aquilo que experimentaram ao longo de sua trajetória (esportiva) e assim, por vezes, desfavorecem a realização de novas práticas.

Podemos dizer que o caso de José apresenta semelhanças com aquilo que Vieira (2007) e Figueiredo (2004) descrevem. Queremos, porém, salientar que, no caso de José, essa cultura esportiva pode ter sido pouco questionada durante seu período de formação inicial, já que, como o próprio docente explicita, sua formação deu-se em um currículo tradicional-esportivo, no qual se privilegiava a prática. O professor parece refém de uma espécie de senso-comum presente na área, que é o de que o esporte educa, ou seja, o simples envolvimento com o esporte teria um efeito educativo positivo.

Em função dessa crença, que está presente também no imaginário social mais amplo, o professor acaba por abster-se de sua função docente, que é a de mediar pedagogicamente esse conteúdo (observe-se que aqui não estamos fazendo julgamento de valor acerca do tipo de mediação pedagógica. Estamos nos referindo apenas à sua ausência, pelo menos de forma intencional). O que percebemos, assim, é que a supervalorização do esporte acaba por provocar uma pseudovalorização da EF em função de uma desvalorização da prática pedagógica desses professores. A não intervenção parece justificar-se, então, por esse valor quase mágico do esporte.

\section{CONSIDERAÇÕES FINAIS}

Como vimos, é possível identificar uma série de fatores que podem ser considerados como determinantes, condicionantes, 
influenciadores do desinvestimento pedagógico. Particularmente, no caso apresentado, o trabalho de campo permitiu-nos apontar três fatores possivelmente ligados ao fenômeno.

Entendemos que esses fatores identificados e nomeados ou nomeados e, por conseguinte, identificados, não agem isoladamente, mas atuam em rede de forma complexa. Optamos, portanto, por abordar/compartilhar, em nossas considerações finais, uma dificuldade teórica enfrentada na pesquisa. Essa dificuldade está relacionada com a complexidade do fenômeno e com suas características. Complexidade que parece resistir a modelos monocausais e mesmo multifatoriais, até porque, além da infinidade de variações possíveis, parecem ter pesos diferenciados em diferentes casos.

É preciso alertar, então, para os problemas ou dificuldades em estabelecer uma teoria explicativa que pudesse ser aplicada a distintos e variados casos concretos, no sentido de prever o comportamento do fenômeno. Talvez seja possível, apenas, identificar os processos relacionados com o fenômeno e reconhecer a singularidade de suas expressões concretas.

Nesse sentido, entendemos que a teorização deva, talvez, continuar buscando encontrar regularidades ou características comuns aos processos e fenômenos, porém, deve-se alertar para o fato de que, apesar disso, tais teorias não possuem força preditiva, já que as práticas (sociais e, portanto, humanas) são simultaneamente singulares. As teorias oferecem-se como ferramentas a serem atualizadas de forma situativa, ponto de partida para uma construção particular e situada. 


The practices of pedagogical divestment in the
school Physical Education
Abstract: This article describes an investigation on
the divestment of the Physical Education (PE) teacher
regarding his pedagogical function. For this, the
methodologies of life stories and ethnographic case study
were used. We also examined the elements involved in
the production of a school culture. The collected data
were analyzed in three categories: a) PE as a curricular
component: does the school divest as well?; b) The
difficulty in operating the mediation between theory
and practice; c) Sport as a content of PE classes.
Keywords: Faculty. Conflict. Professional rule. Sports.

Las práticas de lá desinversión pedagógica en
la Educacíon Física escolar
Resumen: Investiga la no investidura del maestro de
Educación Física (EF) en relación a su función peda-
gógica, utilizando la metodología historia de vida y el
estudio de caso etnográfico. Para ello, estudia también,
elementos involucrados en la producción de una cul-
tura escolar. Los datos producidos son analizados
valiéndose de cuatro categorías: a) La EF como compo-
nente curricular: la escuela también desinvierte? b)
La dificultad de desarrollar la mediación entre la teoría
y la práctica; c) El deporte como contenido de las
clases de EF.
Palabras clave: Docentes. Conflito. Rol profesional.
Deportes.

\section{REFERÊNCIAS}

BETTI, Irene Conceição Rangel; BETTI, Mauro. Novas perspectivas na formação profissional em educação física. Motriz, Rio Claro, v. 2, n. 1, p. 10-15, jun. 1996.

BOGDAN, Robert; BIKLEN, Sari. Investigação qualitativa em educação: uma introdução à teoria e aos métodos. Porto: Porto, 1994.

BRACHT, Valter. Sociologia crítica do esporte: uma introdução. 3. ed. ljuí: Unijuí, 2005.

BRASIL. Lei de Diretrizes e Bases da Educação Nacional. Lei no 9394 de dezembro de 1996. Estabelece as diretrizes e bases da educação nacional. Diário Oficial [da] República Federativa do Brasil. Brasília, DF, 1996.

CAPARROZ, Francisco Eduardo. Entre a educação física na escola e a educação física da escola. Vitória: CEFD - UFES, 1997. 
CAPARROZ, Francisco Eduardo; BRACHT, Valter. O tempo e o lugar de uma didática da educação física. Revista Brasileira de Ciências do Esporte, Campinas, v. 28, n. 2. p. 21-37, jan. 2007.

FIGUEIREDO, Zenólia Christina Campos. Formação docente em educação física: experiências sociais e relação com o saber. Revista Movimento, Porto Alegre, v. 10, n. 1, p. 89-111, jan./abr. 2004.

FORQUIN, Jean-Claude. Escola e cultura: as bases sociais e epistemológicas do conhecimento escolar. Porto Alegre: Artes Médicas, 1993.

GONZÁLEZ, Fernando Jaime; FENSTERSEIFER, Paulo Evaldo. Educação física e cultura escolar: critérios para identificação do abandono do trabalho docente. In: CONGRESO DE EDUCACIÓN FÍSICA: REPENSANDO LA EDUCACIÓN FÍSICA, 2006, Córdoba. Actas del Congreso de Educación Física: repensando la Educación Física. Córdoba: Ipef, p. 734-746, 2006.

HUBERMAN, Michel. O ciclo de vida profissional dos professores. In: NÓVOA, A. (Org.). Vidas de professores. Porto: Porto, p. 31-61, 1995.

MARAUN, Heide-Karen. Ensino-aprendizagem aberto às experiências: sobre a gênese e estrutura da aprendizagem autodeterminada na educação física. In: KUNZ, E.; TREBEL, A. H. (Org.). Educação física crítico-emancipatória: com uma perspectiva da pedagogia alemã do esporte. ljuí: Unijuí, p. 177-202, 2006.

METODOLOGIA do ensino da educação física. São Paulo: Cortez, 1992.

VAGO, Tarcísio Mauro. Esporte da escola, esporte na escola: da negação radical à tensão permanente: um diálogo com Valter Bracht. Movimento, Porto Alegre, v. 3 , n. 5, p. 4-17, 1996.

. A educação física na cultura escolar. In: BRACHT, V.; CRISÓRIO, R. (Org.).

A educação física no Brasil e na Argentina. Campinas: Autores Associados, p. 197-221, 2003.

VIEIRA, Carmen Lúcia Nunes. Memória, esporte e formação docente em educação física. 2007. 112f. Dissertação (Mestrado em Educação) - Programa de PósGraduação em Educação, Universidade Federal de Santa Catarina, Florianópolis, 2007.

Pesquisa financiada pelo CNPq

Recebido em: 02.10.2009

Aprovado em: 27.10.2009

Movimento, Porto Alegre, v. 16, n. 02, p. 129-147, abril/junho de 2010. 